\title{
Innovation in Teaching Multicultural Future Specialists in Kuzbass Coal Mining Region: a Flipped Classroom Approach
}

\author{
Svetlana Kolomiets $^{1,{ }^{*}}$, Elena Medvedeva ${ }^{2}$, and Alena Perevalova ${ }^{1}$ \\ ${ }^{1}$ Kemerovo State University, Institute of Philology, Foreign Languages and Media Communication, \\ Department of Foreign Languages, 650000, 6 Krasnaya st., Kemerovo, Russian Federation \\ ${ }^{2}$ Kemerovo State Medical University, Foreign Students Office, 650056, 22A Voroshilova st., \\ Kemerovo, Russian Federation
}

\begin{abstract}
In the era of globalization export of education has greatly increased all over the world and the Russian Federation is not an exception. Multicultural classes filled with students of different nationalities, cultural backgrounds and languages put a new challenge before the educators. One of the possible solutions to create an equally successful learning environment for all students is applying flipped classroom approach which is connected with the reasonable use of ICT. The article discusses the principles of organization of the flipped class as well as its main characteristics. The authors study the effectiveness of flipped classroom in language learning and describe mobile applications, Internet resources and online services that possess high didactic potential for blended learning. The paper gives the analysis of flipped classroom approach advantages and disadvantages on the results of survey carried out while teaching future specialists in Kuzbass. The outcomes of the study revealed that the main benefit of the flipped classroom approach in ESL teaching is the improvement of students' achievements and therefore their motivation and satisfaction. Among the significant drawbacks of the approach the dependence on technologies and students` reluctance to learn new material autonomously via online resources are mentioned.
\end{abstract}

\section{Introduction}

Global trends in the development of education have led to the influx of students from neighbor countries into the Russian universities. This requires the implementing of new teaching approaches, adjusting the process of study to the modern situation. In fact, cultural diversity implies not only ethnicity and race, but language too. Cultural and language barriers provoke learning difficulties among foreign students. They quite often experience obstacles in communication since they hardly know either the Russian language or the Russian culture. Culturally diverse learning environment encourages university teachers to use new teaching methods, in conjunction with the most up-to-date teaching materials and cutting-edge learning technologies. The primary responsibility of a teacher is to develop a

*Corresponding author: kolomsvetlana@yandex.ru 
learning environment where all students feel motivated to learn within the boundaries of a classroom.

Kuzbass, being one of the biggest coal-mining centres of Russia has increased its popularity among the foreign students as a modern developing educational centre. Many students from different countries choose it as their educational destination. Today, students from Kazakhstan, Kyrgyzstan, Uzbekistan, Tajikistan and Turkmenistan make up the majority of the number of foreign students receiving higher education in universities of Kuzbass. Despite the fact that in the past Russia had close cultural ties with these countries, and students who come from these countries are expected to understand the culture of our country, they grew up in the states that after the collapse of the Soviet Union continued their unique development in the field of education and culture. As a result, educators and students face new challenges associated with intercultural and language barriers. Most of today's students from near-abroad have poor knowledge of Russian, they are unfamiliar with the Russian culture, demonstrate lack of self-control, and have a tendency to learn material more slowly. The students need the teachers' help not only in mastering their future profession but also in learning the Russian language, better understanding the Russian culture and developing new skills of learning and collaboration. As for the Russian students studying in the multinational groups, they also need to cooperate with the people of a different culture and nationality for a mutual benefit.

It should be also noted that the formation of communication competence is one the main objectives of university education as it helps to adapt international experience by the future professional [1] and is a key part of global competence providing the ground for intercultural communication. The students nowadays have to deal with a multilingual (and multicultural) environment which determines the need for the formation of intercultural competence based on the development of critical thinking skills, intercultural communication skills, tolerance and respect to the realities of other cultures [2].

Meanwhile, it is necessary to outline that although students come from various cultures they all are so-called digital natives. They have grown up using technology and the Internet, and therefore, feel more at home in the online world [3]. Today's students seek a learning environment completely different from a traditional classroom. They belong to a Digital Age and prefer e-learning that pushes their learning capacity with altering strategies and teaching practices. They want to be active and engaged players throughout the learning course.

The teaching methods at the disposal of educators can vary a lot and include games, cases, projects, MOOCs, etc [4]. Yet, there is one common link among all of them. Today they all are based on the usage of information technology. ICT, web-sources, any kind of mobile applications and e-learning have become an important and inherent part of educational process $[5,6]$. It is especially significant for the training of mining specialists as their future profession demands for a high technological (computer) literacy on the one hand and for developed communication skills on the other. In the modern world no developed industry can exist in isolation of the region. And mining engineers have to exchange their ideas on the international level.

The professionals engaged in this industry have to understand the complex interdisciplinary character of their activities since the production cannot be organized properly without taking into consideration such factors of influence as biological, ecological, social, economical, etc. Mining engineers should be aware of new trends and investigations in the spheres connected with the coal-mining industry, they need to analyze and evaluate the specific features of new methods of work and apply them in the best possible way.

Thus, in the new era of teaching, technology was called upon to provide teachers with the tools for working in a multicultural and multilingual class. The blooming of technology 
has resulted in the occurrence and development of teaching practices that combine learning and technology (e.g. blended learning, flipped learning, gamification, online learning, 1:1 learning etc.). The model of the flipped classroom has gained popularity in higher education today. This model has proven to be effective in the transition to more flexible, effective, active, and student-centered teaching.

In Cambridge Dictionary the term "flipped classroom" is defined as a teaching method in which students first learn about a new subject at home, especially online, and then have discussions on it in class [7]. The term "Flip" stands for:

F ("F"lexible Environment) - corresponds to the flexible character of the place and time of learning;

L ("L"earning Culture) - marks a shift from teacher centered approach to student centered one;

I ("I"ntentional Content) - highlights the provision of both fluency and development of students' cognitive understanding);

P ("P"rofessional Educator) - stresses the increased responsibility of flipped classroom educators as they are to continuously observe students during the course, evaluate their studies and provide the timely and sufficient feedback.

Since the educators in different countries use flipped classroom with various methods, this caused changing of a flipped classroom concept to a flipped classroom approach. It is emphasized that this new approach can be used with different learning methods [8].

Despite the teaching methods used the effectively organized learning process should consist of three main elements: instructional videos, in-class collaboration and observationfeedback-assessment. The first is necessary to accompany with the guiding questions for better comprehension while the second and the third have to be designed in such a way as to provide the bridge between the instructional videos and collaborative activities in the class and to promote the deepened learning and contribution of every student [9].

At present we can speak about three main models of organizing flipped classroom learning: traditional, partial and holistic. The first model is characterized by the transition of new material acquisitionto home place and working on this material onto class. The second model is in reality a deviation of the first with such a difference that the students are encouraged to watch the videos on the new topic out of class but are not punished in case of failure to do it. The last model is based on thorough monitoring all the students' activities outside regular (synchronous) classes as all the materials and activities are located on some platform providing recording of the students' progress and performance and allowing the educators to analyze the teaching process and the results.

Presumably this approach seems to be a perfect choice for university teachers as it meets the learning demands of students in a culturally diverse class. Flipped classroom provides students with such learning opportunities as:

- independent and active learning;

- cooperative learning;

- collaborative learning;

- e-learning;

- cognitive learning;

- project-based learning.

So, the flipped classroom approach serves to reach all students in the classroom and maintain high standards of education. In our paper we would like to analyze the potential of the flipped classroom approach in ELT in a culturally diverse classroom. The purpose of this study is to examine how flipped classroom approach can improve students ' learning outcomes in an English language course and how this approach can contribute to successful collaboration of culturally diverse students. The participants of the study are first and 
second year mining students learning English for professional purposes in polyethnic groups.

\section{Methods}

Used flipped classroom approach, which is considered to be quite a new model of blended learning for Russian education, allowed students to learn new grammar and vocabulary, organize independent and classroom work in a new, innovative form. Before working in a classroom, the students watched video tutorials and slide presentations (which let them visualize the learning material as much as possible), studied additional material (texts, audio, video), questions for discussion in the lesson and in the training blog, using digital teaching aids and Internet resources.

In this way the students got acquainted with grammar material, developed phonetic skills, learned and practiced vocabulary necessary for discussing general topics and professional vocabulary as well, prepared for communicative activities that were carried out in the classroom. Thus, at the lesson students managed to perform interactive tasks taking part in conversations, role-plays, group projects, etc., which encouraged deeper mastering the learning material.

When working independently, students monitored the level of learning new material through self-assessment using self-checking tests, while in the classroom this was controlled with the help of educational computer games, interactive and project activities, role-playing games, and discussions.

In addition, taking into account the clip-like thinking of a modern student as a feature of the perception and processing of information in the digital world, we used the microlearning method, which involved splitting the educational material in any form (text, audio, video) into concise modules, as well as changing the formats of tasks designed for a limited run time (usually up to 15 minutes).

As a means of micro-learning, in order to implement a communicative approach in the process of teaching a foreign language to students of different ethnic groups and nationalities, we used mobile technologies that contributed to the active and motivated learning and developing the skills necessary for professional activities and business communication in the modern digital world.

Currently, researchers classify mobile applications according to functional characteristics and didactic properties. They distinguish the following categories: communicative, reference and resource, collaborative, documenting, multimedia, search and navigation, gaming applications $[10,11]$. Owing to the high didactic potential, mobile education applications have been actively integrated into the educational process. They allowed us to organize not only students' autonomous learning, but also group work and creative project activities. We used mobile applications for real-time feedback, surveys, self-monitoring and group assessment, visualization and structuring of educational content, searching and exchanging of information, etc.

In order to learn and master lexical skills, we chose the Quizlet service, which allowed foreign students to study new vocabulary in a convenient form, to translate it into their native language, if necessary, to learn and expand general and professional vocabulary at a convenient time, conditions and terms. Such preparatory work contributed to improving vocabulary necessary for communication in the classroom without using either the Russian language or electronic translators.

For mastering pronunciation skills the students were offered such applications as Pronunciation: Clear Speech, Sounds: Pronunciation App, Speak English Pronunciation, English Pronunciation Training. The choice of application depended on how well pronunciation skills had been developed by each student and their personal preferences. For 
example, the Sounds: Pronunciation App (designed by Macmillan Publishers Ltd) allowed foreign students to listen to the correct pronunciation of vowels and consonants, learn English transcription, record and practice their own pronunciation, and do self-assessment tests. Students experiencing difficulties in understanding the technique of pronouncing sounds could use the descriptions and pictures (with the position of the tongue and lips) offered in these applications that facilitated the process of working on the correct pronunciation. The applications also offer a real possibility for watching educational videos, evaluating and tracking progress, repeatedly doing exercises, which allowed students to practice without the teacher's supervision.

Additionally, we used the application Learn English Grammar (British Council), which served as a helpful addition to the learning video and encouraged students to study necessary grammar topics, work on them using exercises of various formats with immediate evaluation of the result.

In order to develop listening skills, practice listening comprehension, learn to recognize a variety of modern dialects and accents of the English language, we used the ESLvideo service, which provides not only video materials for different levels of language proficiency (Beginning, Intermediate, Advanced), but also the possibility for prompt checking learning / understanding the content using ready-made tests, or prepared by the teacher directly.

The use of the application Seesaw and the Padlet service made it possible to organize independent individual and group work of foreign students with the aim of developing the skills and abilities necessary for communication (verbal and written) in English in their future professional activities. The students recorded their own audio and video files, wrote essays on specific topics for discussions, and published these materials on the website (Padlet) or their portfolio (Seesaw). The capabilities of these ICTs allowed the students to exchange opinions / ideas / thoughts, write comments, carry out peer correction and analysis, work on co-projects and presentations.

When organizing work in polyethnic groups, it is absolutely essential to promote the development of students' skills to build intercultural interaction, taking into account national and sociocultural experiences. Using the application and online platform Nearpod, students had the opportunity to create presentations of the culture of their nations or ethnic groups, their peculiar features, similarities and differences; insert audio and video content into the presentations; work in groups or individually; provide support and mutual assistance; in fact, realize intercultural communication, since they are all representatives of different cultures and nationalities. This platform also provided a means of demonstrating the material, as well as promoting the organization of testing its understanding through a variety of interactive test and game tasks, including open-ended questions, matching pairs, quizzes, drawing and brainstorming tasks, filling in gaps, memory tests, and polls.

Such work has contributed to successful interaction in a modern multicultural environment, creating effective behavioral patterns in various situations of intercultural communication based on mutual enrichment and respect among people of different cultures.

\section{Results}

At the end of the first year of study, we conducted a survey of the students in order to collect high-quality experimental data. In addition, we analyzed the results of pedagogical observation carried out in the process of experimental work. It should be noted that almost all of the students surveyed (99\%) highly appreciated the effectiveness of using the ICT technologies described above, emphasizing their capabilities such as presented in Tab. 1: 
Table 1. Positive features of the flipped classroom approach according to the students' survey.

\begin{tabular}{|c|c|}
\hline The feature marked & Number of students, $\%$ \\
\hline $\begin{array}{c}\text { studying, practicing and revising learning material at } \\
\text { a convenient time, favorable conditions and a } \\
\text { comfortable place }\end{array}$ & 100 \\
\hline $\begin{array}{l}\text { visualizing and audio support of learning material, } \\
\text { which stimulate its studying }\end{array}$ & 100 \\
\hline $\begin{array}{l}\text { the opportunity to chat / consult / discuss issues / } \\
\text { exchange ideas at any time with classmates }\end{array}$ & 98 \\
\hline $\begin{array}{c}\text { mutual support and assistance through forums, blogs, } \\
\text { and comment fields on the online platforms and } \\
\text { services used }\end{array}$ & 93 \\
\hline $\begin{array}{l}\text { active learning and improving general and } \\
\text { professional vocabulary, which greatly facilitates } \\
\text { participation in discussions, role-playing games, } \\
\text { communication and other communicative types of } \\
\text { educational activities in practical classes }\end{array}$ & 89 \\
\hline $\begin{array}{l}\text { indirect control and assessment of knowledge, which } \\
\text { help to relieve internal stress and fear of bad or low } \\
\text { grades }\end{array}$ & 87 \\
\hline $\begin{array}{l}\text { the possibility of translating unfamiliar words and } \\
\text { expressions into their native language }\end{array}$ & 85 \\
\hline $\begin{array}{l}\text { the opportunity to receive support and timely } \\
\text { assistance from the teacher }\end{array}$ & 82 \\
\hline $\begin{array}{l}\text { organizing co-operative project work without leaving } \\
\text { home (or dormitories) }\end{array}$ & 79 \\
\hline
\end{tabular}

As one of the major drawbacks of the training format used, students noted some problems related to possible unstable operation of the Internet $(27 \%$ of the students surveyed). Some students accepted the need to learn how to organize independent work and develop the skill of planning and exercising conscious control of time spent on specific activities (time management) (31\% of the total number of respondents).

The analysis of the results allowed us to note the effectiveness of the used flipped classroom approach, which contributed to the stimulation of interest and motivation; helped to overcome psychological barrier and fear in communicative situations. All this have encouraged intercultural interaction, developing the necessary skills in an interactive environment, improving the quality of knowledge gained, facilitating the learning process, activating both independent and group work.

\section{Discussion}

In order to use the flipped classroom approach in ESL teaching firstly the teachers themselves need to "flip" their mind and preparation for lessons. The implementation of the flipped classroom approach enforces teachers to devise independent online tasks and assess the readiness and willingness of students to complete such piece of work on their own. The 
flipped classroom approach is intended to improve students` autonomous learning skills. It is a paramount aim of a teacher to train students to watch educational videos or listen to educational media news in a meaningful way. In other words, students are required to possess basic skills for independent learning. Due to flipped classroom approach students are taught to take the responsibility for their learning progress, they gain necessary skills and abilities for lifelong learning.

The flipped classroom fosters students for further online education. It is inseparably connected with technologies and the Internet as teachers use various online resources to create or publish the materials for independent study. Within the flipped classroom approach students are taught how to work with online resources and learn to be responsible and thoughtful learners. The "digital part" of the flipped classroom approach enables students to prepare for further online-based learning that is globally used by universities via various online learning platforms such as Coursera, Udemy, Universarium for education or retraining of specialists. In fact, e-learning platforms offer video lectures, informative videos, comprehension online tests and online forums as means of teaching. Thus the students who were exposed to education within the flipped classroom approach have all necessary skills and abilities to continue their education in any university of the world via online learning platforms.

The flipped classroom implies that all learning materials are always accessible for students on the Internet or in mobile application so students who miss a class are able to receive necessary materials and teacher's support via modern technologies. Once the materials for a flipped classroom are developed, they are available for students for revision and mastering language skills.

The conducted research has proven that the major part of the English course content can be used within the frame of a flipped classroom approach. Due to the fact that the information delivery stage is done at home by students on their own they are able to study new material at their own pace and at any preferable time for them. It is very important because in the situation of students with different level of knowledge, different models of perception, different pace of acquisition the new material the time spent on explanation can be really long. Flipped classroom approach is perfect to avoid wasting time by the students who are faster in understanding new material and gives a good opportunity for those who need more time and thinking over. Thus, it helps to overcome the limitations of the class time.

Outside of the classroom students recall relevant background knowledge, gain knew knowledge and check it via lecture videos, online tests, language learning mobile applications, etc. This approach is especially useful and profitable for mastering lexical skills and such skills as pronunciation, reading, writing and listening. Foreign students are able to use their mother tongue to understand and complete the tasks given in English reducing or even skipping teacher's instructions in the Russian language. Students are able to prepare better for the upcoming lesson.

In fact, there are some skills that need to be practiced only in class under the supervision of a teacher. Under the flipped classroom approach, during classes students are exposed to do higher level cognitive activities such as application, analysis, synthesis and evaluation of knowledge gained at home. Group work, work in pairs, discussions, rope-plays, simulative real-life conversations are beneficial for mastering communicative competence of students.

The adoption of the flipped classroom approach in ESL teaching can be very rewarding. It permits not to waste time on explanation when students have passive roles of listeners but make them to be active participants of an educational process. When theoretical part of a lesson is done at home the interactive period within a class increases a lot. The interaction between a teacher and students enhances, a teacher has more time to fulfill the learning and emotional demands of students. The class time is transformed into dynamic, interactive 
learning environment where each student is involved into active learning. Face-to-face interaction within flipped classroom implies group working, problem solving and discussion.The results of research have revealed that teamwork is essential and inseparable part of a class within flipped classroom approach in culturally diverse learning environment. Case studies, projects and business role-plays organized by a teacher for assessment or revision of work done at home establish conditions for cooperating and collaborating learning of students. Cooperative and collaborative project work aims to stimulate and develop students' skills of intercultural interaction. Due to cooperative pair work students with different cultural backgrounds gain a more comprehensive understanding of another culture, break cultural and ethnic stereotypes. Peer teaching is also efficient in groups of students with mixed abilities.

The role of a teacher changes as well. The main teacher's role in the frame of flipped classroom approach is a facilitator rather than a mentor. The teacher does not deliver direct instructions to students any more. In a flipped classroom the teacher guides students to think and discuss, and gives them feedback and professional advice. Although she/he still has to check the knowledge and skills that students have acquired at home. The analysis of the study shows that with the flipped approach the teacher's dedication to work and satisfaction with students' learning results have increased.

At the same time the teacher has more challenges before him as all the materials should be prepared (or chosen) carefully to ensure the high quality of video materials and thorough preparation of the activities. All this requires a lot of time, knowledge and understanding the students' interests.

Although, the flipped classroom approach has some obvious and indisputable benefits and challenges in ESL teaching there are still some disadvantages. One of the major drawbacks is students 'access to the technology. Today not all students have tablet PCs, laptop computers or smartphones with wireless internet at home. In a traditional classroom, a teacher cannot provide all students with necessary gadgets if they do not have any.

The second hurdle in the implementation of the flipped classroom approach can be the lack of motivation. Some students demonstrated the lack of desire and enthusiasm to do online tasks as they are overloaded with computer-mediated communication or just have easier/ more interesting things to do. Here each case should be analyzed independently and paid more attention too. In some cases, the progress of the groupmates demonstrating better results and successfully involved in the interesting activities in the class can be a stimulus, in others, it can be an individual extra task or specially arranged pair work.

Another major drawback of the flipped classroom is that quite often students are exposed to too much online content for independent learning. Bulky volume of pre-class learning materials discourages students. They come to class unprepared and that prevents them from active classroom learning. The incapability of teachers to offer suitable pre-class tasks to students can lead to the total failure of the flipped classroom approach in ESL teaching.

\section{Conclusion}

Educational settings of modern universities are characterized by the limitation of classroom time and recourses. It can become a real challenge in the situation of multicultural class of students with mixed abilities. The flipped classroom approach can be a good digital solution to overcome these limits of modern educational environment. Its main advantages are: better understanding of the material on the part of the learners; saving time in the class and spending it onto interaction with the groupmates and the teacher; increase of the critical thinking abilities. All these features are especially relevant in the multicultural class as they 
help to better understanding of a different culture and promote the development of communication competence in greater degree.

In spite of having a lot of benefits, flipped classroom approach also has some drawbacks the most significant of which are lack of access to digital technology and poor motivation on the part of the students. Yet, in case of proper planning, preparation and organization of the learning process the advantages of flipped classroom approach prevail.

The use of the flipped classroom approach in teaching multicultural and multilingual students is highly rewarding as it enables foreign students to integrate gradually in learning environment of Russian universities. At the same time it is reasonable to continue research, firstly, to ensure progress and affirm the obtained results. Secondly, It might also be important to describe and analyze the pair work and interaction of students from different ethnical and cultural backgrounds within the flipped classroom approach.

\section{Acknowledgement}

The reported study was funded by RFBR according to the research project № 19-01300805

\section{References}

1. N. Godzhaeva, T. Logunov, M. Lokteva, and P. Strelnikov, E3S Web Conf., 105, 04037 (2019)

2. I. Pevneva, P. Edmunds, and A. Smirnova, E3S Web Conf., 105, 04017 (2019)

3. N. Hockly, ELTJ 65:3, 322-325 (2011)

4. S. Kolomiets, E. Medvedeva, A. Perevalova, E3S Web Conf., 105, 04033 (2019)

5. N. Tunyova, E3S Web Conf., 105, 04041 (2019)

6. R. Islamov, O. Greenwald, N. Tunyova, E3S Web of Conf., 41, 04041 (2018)

7. Cambridge Dictionary. URL: https://dictionary.cambridge.org/

8. F. Ozdamli, G. Aşıksoy, WJET, 8, 98 (2016) doi:0.18844/wjet.v8i2.640

9. H. W. Marshall, Three reasons to flip your classroom (Penns, London, 2013)

10. T. Cherner, J. Dix, C. Lee, CITTE, 14:2, 158-193 (2014)

11. O. Chergui, A. Begdouri, D. Groux-Leclet, IJIET, 7, 324-330 (2017) 